\title{
A 20(S)-protopanaxadiol derivative PPD12 reverses ABCB1-mediated multidrug resistance with oral bioavailability and low toxicity
}

\author{
SHUNFENG WEI ${ }^{1,2}$, WANTAO CHEN ${ }^{2}$, LIHONG HU $^{3}$, JINSONG PAN $^{1}$ and XU WANG ${ }^{2}$ \\ ${ }^{1}$ Department of Stomatology, Shanghai General Hospital, Shanghai Jiao Tong University School of Medicine, \\ Shanghai 200080; ${ }^{2}$ Department of Oral and Maxillofacial-Head and Neck Oncology, \\ Shanghai Ninth People's Hospital, Shanghai Jiao Tong University School of Medicine, Shanghai 200011; \\ ${ }^{3}$ Shanghai Research Center for Modernization of Traditional Chinese Medicine, Shanghai Institute of Materia Medica, \\ Chinese Academy of Sciences, Shanghai 201203, P.R. China
}

Received October 29, 2017; Accepted July 4, 2018

DOI: $10.3892 / 01.2018 .9338$

\begin{abstract}
The ATP-binding cassette subfamily B member 1 (ABCB1) is a transporter that mediates multidrug resistance (MDR) against chemotherapy, which leads to decreased patient survival. To inhibit ABCB1 activity in MDR cancer cells, the authors previously designed and synthesized a derivative from 20(S)-protopanaxadiol (PPD) PPD12 and verified its efficacy in ABCB1-overexpressing cancer cells. In the present study, the reversal effect of PPD12 on MDR was further evaluated and its pharmacokinetics and toxicity in vitro and in vivo were investigated. Incubation with PPD12 may significantly ameliorate the drug resistance of $\mathrm{KB} / \mathrm{VCR}$ cells in a short time and maintain its reversed MDR ability for increasing time periods. In assays on a series of CYP450 activities, PPD12 demonstrated slight inhibition effects on the majority of enzymes. The bioavailability of PPD12 was nearly $100 \%$ by oral administration in a mouse model. Single PPD12 oral gavage at either high doses or subchronic low doses, was well tolerated by the mice. In addition, PPD12 at the therapeutic dosage did not significantly increase the toxicity of the chemotherapeutic agent Adriamycin when mice received a combination of the two compounds. In conclusion, PPD12 represents a novel type of $\mathrm{ABCB} 1$ inhibitor that has significant
\end{abstract}

Correspondence to: $\mathrm{Dr} \mathrm{Xu}$ Wang, Department of Oral and Maxillofacial-Head and Neck Oncology, Shanghai Ninth People's Hospital, Shanghai Jiao Tong University School of Medicine, 639 Zhizaoju Road, Huangpu, Shanghai 200011, P.R. China E-mail: wangx312016@sh9hospital.org

Dr Jinsong Pan, Department of Stomatology, Shanghai General Hospital, Shanghai Jiao Tong University School of Medicine, 85 Wujin Road, Hongkou, Shanghai 200080, P.R. China

E-mail:pip0003@163.com

Key words: multidrug resistance, ATP-binding cassette subfamily B member 1, toxicity, pharmacokinetics bioactivity in terms of MDR, high oral bioavailability and low toxicity.

\section{Introduction}

Chemotherapy has contributed significantly to the development of cancer treatment. However, it has some unpleasant features, such as side-effects at therapeutic dosages and multidrug resistance (MDR). As a frontline chemotherapeutic agent, the use of Adriamycin (ADM) can never avoid these problems. To date, researchers have found that a variety of mechanisms are responsible for MDR, including increased drug efflux, reduced drug intake and the induction of anti-apoptotic mechanisms. Inefficient drug absorption is partly due to the overexpression of adenine triphosphate (ATP)-binding cassette (ABC) transporters, which can pump therapeutic agents from cancer cells.

Ginseng has been used in Asian countries for thousands of years as an herbal medicine to prevent and treat diseases (1). Its active ingredients, ginsenosides, have appealed to researchers for their promising anticancer activity and low toxicity $(2,3)$. 20(S)-protopanaxadiol (PPD) is a major gastrointestinal metabolic product and possesses many pharmacological activities, including anti-inflammatory (4), antidepressant (5) and anticancer properties (6-8). However, although PPD acts as an active ingredient and major metabolic product, the amount of PPD in natural herbal medicine is far from meeting clinical needs, which has limited its drug efficiency and clinical application. We have tried to better evaluate its effectivity and improve its industrialized production. On the basis of the literature, the oxidation of the 24,25-double bond is the predominant metabolic pathway of PPD $(9,10)$. Previously, we modified the 24,25-double bond and designed and synthesized a series of PPD derivatives (11). Furthermore, we found that PPD12 could sensitize MDR cancer cells to chemotherapeutic agents in vitro via $\mathrm{ABC}$ subfamily $\mathrm{B}$ member 1 (ABCB1), which is an important member of the $A B C$ family (12). The administration of $100 \mathrm{mg} / \mathrm{kg}$ PPD12 significantly enhanced the inhibitory effect of ADM against a multidrug-resistant tumor in the xenograft model. 
However, further details regarding PPD12 remain unclear. The reverse ability of PPD12 on MDR requires further investigation. Many chemosensitizing agents have had preliminary success but are precluded from clinical use for their toxicity at the doses required to have a therapeutic effect. For PPD12, we briefly explored its reversibility on MDR, but its toxicity has not been established. Previous studies suggested that in clinical settings, the co-administration of a ginsenoside with other therapeutic agents might lead to ginseng drug interactions $(13,14)$. Thus, the toxicity of a single treatment of PPD12 and the role that PPD12 plays in the ADM toxicity must be investigated. In addition to in vitro and in vivo toxicity studies, we investigated PPD12's pharmacokinetics.

\section{Materials and methods}

Cells and regents. The human oral carcinoma cell line KB were obtained from the American Type Culture Collection. The KB cells was originally thought to originate from an oral epidermal carcinoma, but has now been shown to be a HeLa derivative $(15,16)$ and vincristine-selected cell line KB/VCR was subscribed by professor Lihong $\mathrm{Hu}$ from Shanghai Institute of Materia Medica of Chinese Academy of Sciences. All cell lines have been under cell line authentication service and its result showed cell lines could be used for research. Cells were maintained in DMEM supplemented with $10 \%$ fetal bovine serum, 100 units $/ \mathrm{ml}$ penicillin and $100 \mu \mathrm{g} / \mathrm{ml}$ streptomycin at $37^{\circ} \mathrm{C}$ and $5 \% \mathrm{CO}_{2}$. PPD12 was synthesized by our laboratory as previously reported (11). ADM, midazolam, testosterone, phenacetin, bupropion, amodiaquine, diclofenac, s-mephenytoin, dextromethorphan, Ketoconazol, $\alpha$-Naphthoflavone, Ticlopidine, Quercetin, Sulfaphenazole, Ticlopidine, Quinidine, ${ }^{13} \mathrm{C}_{2},{ }^{15} \mathrm{~N}$-acetaminophen and $\mathrm{d}_{9}$-1'-hydroxybufuralol were purchased from Sigma-Aldrich (Merck KGaA, Darmstadt, Germany). Acetonitrile and methanol [high-performance liquid chromatography (HPLC) grade] were obtained from Thermo Fisher Scientific, Inc. (Waltham, MA, USA). All other chemicals were of the highest quality available. A TUNEL staining assay kit was purchased from Wuhan Boster Biological Technology, Ltd. (Wuhan, China).

Cell growth and survival assays. Cell viability was assessed using the MTT assay as previously described (17). Cells were seeded in 96-well microculture plates overnight to allow cell attachment and then incubated with various concentrations of PPD12 and different concentrations of chemotherapeutic agents. Then, MTT reagent was added to each well. After $4 \mathrm{~h}$ of incubation, we photometrically quantified the colored formazan products at $490 \mathrm{~nm}$ using a multiwell plate reader (Bio-Rad Laboratories, Hercules, CA, USA).

Animal toxicity studies. All animal studies were performed in accordance with the Guide for Care and Use of Laboratory Animals (The Ministry of Science and Technology of China, 2006) and the related regulations of the Ninth People's Hospital (Shanghai, China). Forty SPF Balb/c mice (age 4-5 weeks old) were supplied by the Shanghai Laboratory Animal Center (Shanghai, China) and housed under pathogen-free conditions in the animal care facilities of the Ninth People's Hospital affiliated with Shanghai Jiao Tong University. Half of the mice were female, and the other half were male. The mice were divided into four groups, with 5 females and 5 males in each group. Weight-matched groups of mice were used. The control group was treated with a related vehicle. The PPD12 group was treated with PPD12 at $100 \mathrm{mg} / \mathrm{kg}$ via gavage twice weekly for 2 weeks. The ADM group was given ADM at $20 \mathrm{mg} / \mathrm{kg}$ through intraperitoneal injection on the 6th day from the start of the experiment. After pretreatment with PPD12 at $100 \mathrm{mg} / \mathrm{kg}$ twice a week for one week, the combined group received $\mathrm{ADM}$ at $20 \mathrm{mg} / \mathrm{kg}$ via intraperitoneal injection on the 6th day and continued receiving PPD12 at $100 \mathrm{mg} / \mathrm{kg}$ twice a week for another week. This study continued for 3 weeks. Animals were weighed every day. At the end of this experiment, mice were euthanized for subsequent necropsy.

$H \& E$ and TUNEL assay. Animals' tissues were fixed in $4 \%$ formaldehyde, dehydrated with gradient ethanol and embedded in paraffin. The tissue sections $(4 \mu \mathrm{m})$ were dewaxed and rehydrated per a standard protocol. For histological analysis, the sections were stained with hematoxylin and eosin. Once cell got damaged, cells became edematous and deformed and finally got necrosis with its structure disorganized and nuclear fragmentation. And at least 3 tissue samples and 5 fields of view were analyzed to determine the cell damages in each experimental group. $\mathrm{H} \& \mathrm{E}$ assay could partly indicate cell damage but the damaged cells need a specific staining. So we performed TUNEL assay which can specifically distinguish apoptotic cells. For the TUNEL assay, an in situ apoptosis detection kit (Wuhan Boster Biological Technology, Ltd.) was used to detect apoptotic cells in heart tissues. The positive cells were identified, counted (three random fields per slide) and analyzed through ECLIPSE 80i light microscopy (Nikon, Tokyo, Japan).

Pharmacokinetic study. The protocol utilized is based on a previous report (18). PPD12 was administered as a single dose of $10 \mathrm{mg} / \mathrm{kg}$ by tail vein injection or oral gavage into adult male SD rats. At predose and at 0.083, 0.25, 0.5, 1, 2, 4, 8 , and 24 h post-dose, blood was collected from three male rats and immediately processed for plasma by centrifugation for $10 \mathrm{~min}$ at 3,000 $\mathrm{x}$. The resulting plasma was frozen on dry ice, and the samples were stored at $-80^{\circ} \mathrm{C}$ until analysis. Proper measures were taken to minimize any pain and discomfort the rats experienced. All experimental procedures were performed in accordance with the National Institutes of Health Guide for Care and Use of Laboratory Animals (revised 2006). The experiments were performed in compliance with ethical regulations, and the institute's committee approved the protocols. For mouse plasma sample analysis of PPD12, a 0.1-ml aliquot of plasma sample was treated with $0.3 \mathrm{ml}$ of methanol containing $250 \mathrm{nM}$ internal standard (IS) for direct deproteinization. After vortex mixing for $1 \mathrm{~min}$ and centrifuging for $5 \mathrm{~min}$ at $10,000 \mathrm{x} \mathrm{g}, 0.2 \mathrm{ml}$ of supernatant was transferred to a sample vial, and $5 \mu \mathrm{l}$ of the sample was injected onto the LC/MS/MS. The LC was performed on an Agilent 1200 HPLC system (Agilent Technologies, Inc., Santa Clara, CA, USA), and separation was performed at $30^{\circ} \mathrm{C}$ using an Xterra column $(2.1 \times 50 \mathrm{~mm}, 3.5 \mu \mathrm{m}$; Waters Corporation, Milford, MA, USA). 

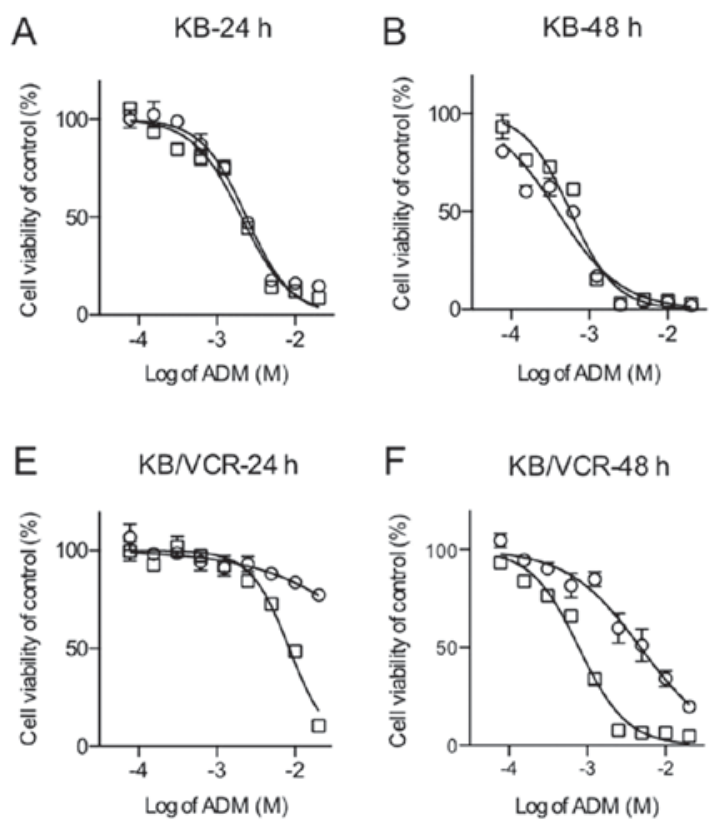
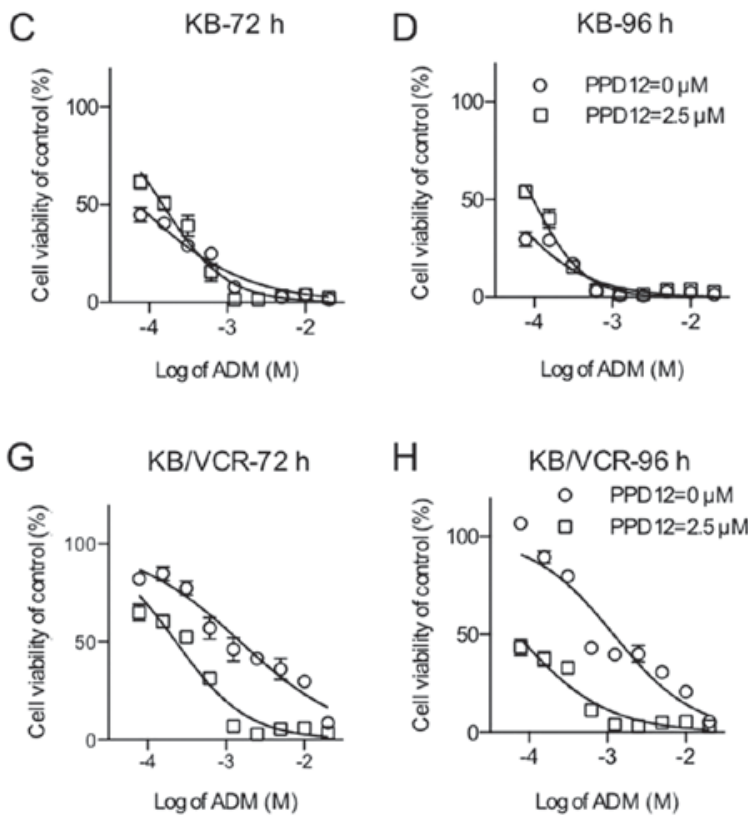

Figure 1. PPD12 ameliorates drug resistance against ADM in KB/VCR cell lines in a time-dependent manner. The KB cell line was treated with ADM and different concentrations of PPD12 for (A) 24, (B) 48, (C) 72 and (D) 96 h. The KB/VCR cell line was treated with ADM and different concentrations of PPD12 for (E) 24, (F) 48, (G) 72 and (H) 96 h. Cell viability was assayed using MTT. ADM, adriamycin; PPD12, 20(S)-protopanaxadiol derivative.

Inhibitory effects of PPD12 on seven major CYP activities in human liver microsomes. The inhibitory potencies $\left(\mathrm{IC}_{50}\right.$ values) of PPD12 on CYP3A4, CYP1A2, CYP2C8, CYP2C9, CYP2C19, CYP2B6 and CYP2D6 activities were evaluated in pooled human liver microsomes using a cocktail of seven CYP substrates and liquid chromatography-tandem mass spectrometry (LC-MS/MS). The incubation mixtures consisted of pooled human liver microsomes $(0.1 \mathrm{mg} / \mathrm{ml}), 1.3 \mathrm{mMNADPH}$, $3.3 \mathrm{mM} \mathrm{MgCl}$, various concentrations of PPD12 or selective inhibitors in dimethyl sulfoxide (DMSO; final concentrations of PPD12 of 0.1-33 $\mu \mathrm{M}$; DMSO $<1 \% v / v$ ) and a cocktail of eight CYP probe substrates, as described previously (19). The CYP substrates were used at concentrations approximating their respective $\mathrm{K}_{\mathrm{m}}$ values: $5 \mu \mathrm{M}$ Midazolam, $120 \mu \mathrm{M}$ testosterone, $50 \mu \mathrm{M}$ Phenacetin, $50 \mu \mathrm{M}$ Bupropion, $5 \mu \mathrm{M}$ Amodiaquine, $7 \mu \mathrm{M}$ Diclofenac, $40 \mu \mathrm{M}$ S-Mephenytoin, or $7 \mu \mathrm{M}$ Dextromethorphan. After a 3-min preincubation at $37^{\circ} \mathrm{C}$, the reactions were initiated by the addition of NADPH; incubation proceeded for $15 \mathrm{~min}$ at $37^{\circ} \mathrm{C}$ in a shaking water bath. The reaction was stopped by placing the tubes on ice and adding $100 \mu \mathrm{l}$ of ice-cold methanol containing IS $\left({ }^{13} \mathrm{C}_{2},{ }^{15} \mathrm{~N}\right.$-acetaminophen for acetaminophen and desethylamodiaquine, $\mathrm{d}_{9}-1$ '-hydroxybufuralol for 4'-hydroxydiclofenac, 4'-hydroxy-mephenytoin and 1'-hydroxymidazolam). The incubation mixtures were then centrifuged $\left(13,000 \mathrm{rpm}\right.$ for $4 \mathrm{~min}$ at $\left.4^{\circ} \mathrm{C}\right)$. All assays were performed in triplicate, and the mean values were used in subsequent calculations.

The metabolites formed from the seven substrates were simultaneously quantified using our previously described LC-MS/MS method. To this end, we employed a tandem mass spectrometer (TSQ Quantum Access; Thermo Fisher Scientific, Inc.) coupled to a Nanospace SI-2 LCsystem (Shiseido, Tokyo, Japan). The column and auto sampler temperatures were $50^{\circ} \mathrm{C}$ and $6^{\circ} \mathrm{C}$, respectively. The mass spectrometer was equipped with an electrospray ionization (ESI) source and operated in positive ion mode. The ESI source settings for metabolite ionization were as follows: Capillary voltage, $4200 \mathrm{~V}$; vaporizer temperature, $350^{\circ} \mathrm{C}$; Capillary temperature, $330^{\circ} \mathrm{C}$; sheath gas pressure, $35 \mathrm{psi}$; and auxiliary gas pressure, 15 psi. Quantification was performed by selected reaction monitoring (SRM) of the $[\mathrm{M}+\mathrm{H}]+$ ion and the related product ion for each metabolite: Acetaminophen, 152.1>110.3; $N$-desethylamodiaquine, 328.1>283.0; 7-hydroxycoumarin, 163.0>107.2; 4'-hydroxydiclofenac, 312.0>231.1; 4'-hydroxy-mephenytoin, 235.1>150.1; 1'-hydroxybufuralol, 278.1>186.1, 1'-hydroxymidazolam, 341.9>324.0; 13C2-15N-acetaminophen 155.1>111.2; and d9-1'-hydroxybufuralol, 287.2>187.0. Analytical data were processed using the Xcalibur ${ }^{\circledR}$ software (Thermo Fischer Scientific, Inc.).

Statistical analysis. Data are presented as the mean \pm standard error of the mean. The body weight data and percentage of apoptotic cells were analyzed using one-way analysis of variance (ANOVA) followed by Dunnett's post hoc test. The $\mathrm{IC}_{50}$ data were analyzed using an unpaired t-test. Statistical analyses were performed with GraphPad Prism, and $\mathrm{P}<0.05$ was considered to indicate a statistically significant difference. Plasma concentration data were used to calculate the PK parameters by a noncompartmental i.v.-bolus input model (WinNonlin 5.0; Pharsight Corporation, Mountain View, CA, USA).

\section{Results}

Effect of PPD12 on reversing drug resistance in $\mathrm{KB} / V C R$ cells with increasing time. PPD12 has been evaluated for its ability to reverse MDR in several cell lines in a dose-dependent manner (20). To better investigate the relationship between the anti-MDR ability and the duration of drug action, KB/VCR and its parent cell line KB were incubated with ADM alone or in combination with $2.5 \mu \mathrm{M}$ PPD12 for different durations of time (24, 48, 72 and 96 h) (Fig. 1). Indeed, KB/VCR cells had a 
Table I. Effect of PPD12 on ADM-MDR reversal in KB/VCR and KB cells.

$\mathrm{IC}_{50} \pm \mathrm{SD}(\mu \mathrm{M})^{\mathrm{a}}\left(\right.$ fold reversal $\left.{ }^{\mathrm{b}}\right)$

\begin{tabular}{lccr}
\cline { 3 - 3 } Compound & Incubation time & KB & \multicolumn{1}{c}{ KB/VCR } \\
\hline ADM & $24 \mathrm{~h}$ & $2.3830 \pm 0.0304(1.00)$ & $150.900 \pm 0.2891(1.00)$ \\
& $48 \mathrm{~h}$ & $0.3898 \pm 0.0373(1.00)$ & $4.782 \pm 0.0476(1.00)$ \\
$72 \mathrm{~h}$ & $0.0713 \pm 0.0510(1.00)$ & $1.521 \pm 0.0492(1.00)$ \\
& $96 \mathrm{~h}$ & $0.0351 \pm 0.0736(1.00)$ & $1.193 \pm 0.0540(1.00)$ \\
$\mathrm{ADM}+2.5 \mu \mathrm{M}$ PPD12 & $24 \mathrm{~h}$ & $2.0640 \pm 0.0242(1.15)^{\mathrm{c}}$ & $8.4310 \pm 0.0265(17.90)^{\mathrm{f}}$ \\
& $48 \mathrm{~h}$ & $0.5732 \pm 0.0265(0.68)$ & $0.7795 \pm 0.0213(6.13)^{\mathrm{e}}$ \\
& $72 \mathrm{~h}$ & $0.1493 \pm 0.0321(0.48)$ & $0.2292 \pm 0.0328(6.64)^{\mathrm{d}}$ \\
& $96 \mathrm{~h}$ & $0.0968 \pm 0.0241(0.36)$ & $0.0692 \pm 0.0550(17.24)^{\mathrm{d}}$
\end{tabular}

${ }^{\mathrm{a}} \mathrm{IC}_{50} \pm \mathrm{SD}(\mu \mathrm{M})$ values are represented as the mean $\pm \mathrm{SD}$ of three independent experiments performed in triplicate. ${ }^{\mathrm{b}} \mathrm{The}$ fold reversal of $\mathrm{MDR}$ was calculated by dividing the $\mathrm{IC}_{50}$ of cells with $\mathrm{ADM}$ and $\mathrm{PPD} 12$ by that with $\mathrm{ADM}$ alone. ${ }^{\mathrm{C}} \mathrm{P}<0.05,{ }^{\mathrm{d}} \mathrm{P}<0.01,{ }^{\mathrm{e}} \mathrm{P}<0.001$ and ${ }^{\mathrm{f}} \mathrm{P}<0.0001 \mathrm{vs}$. the ADM group at the same time point. ADM, adriamycin; PPD12, 20(S)-protopanaxadiol derivative; SD, standard deviation.

higher tolerance of ADM than did KB cells. For KB cells, the ADM dosage-effect curve was close to the PPD co-treatment curves. In addition, in the first $24 \mathrm{~h}$, the absence of PPD12 could significantly sensitize KB to ADM. However, for incubations of longer duration, this type of sensitivity did not exist.

In contrast to the KB's response, KB/VCR cells were much more vulnerable to co-treatment with PPD12 and ADM. A summary of the $\mathrm{IC}_{50}$ values is shown in Table I. As the incubation time increased, the $\mathrm{IC}_{50}$ values of $\mathrm{KB}$ cells to $\mathrm{ADM}$ treatment ranged from 2.383 to $0.0351 \mu \mathrm{M}$, whereas the $\mathrm{IC}_{50}$ values of $\mathrm{KB}$ cells to the combination of ADM and PPD12 varied from 2.064 to $0.0968 \mu \mathrm{M}$. In contrast to the response observed in $\mathrm{KB}$ cells, within $24 \mathrm{~h}$ of incubation, the addition of PPD12 sharply decreased the $\mathrm{IC}_{50}$ value of $\mathrm{KB} / \mathrm{VCR}$ cells to ADM treatment from 150.9 to $8.431 \mu \mathrm{M}$, which is nearly an 18 -fold reversal. After 48, 72, and $96 \mathrm{~h}$ of incubation, the $\mathrm{IC}_{50}$ values of $\mathrm{KB} / \mathrm{VCR}$ to $\mathrm{ADM}$ decreased from 4.782 to $1.193 \mu \mathrm{M}$, and those of KB/VCR to the combination of ADM and PPD12 were all less than $1 \mu \mathrm{M}$; they were all near the values of the $\mathrm{KB}$ cells to $\mathrm{ADM}$ alone or the combination of ADM and PPD12. PPD12 helped ADM agents reach a satisfactory anti-MDR activity level within a short period of time and keep its effectiveness in the long term.

Pharmacokinetic interactions of PPD12 with CYP450 in human liver microsomes. It is postulated that most metabolic drug interactions can be attributed to inhibition or induction of the drug-metabolizing cytochrome P450 (CYP or P450) enzymes (21). However, ginseng and its extract seem to have different impacts on CYP, and the effect that PPD12 has on CYP450 is unknown. To evaluate the influence of PPD12 on the CPY450 enzymes, their activities were examined with pooled human liver microsomes, and selective inhibitors were used as a positive control. For the selective inhibitors, the $\mathrm{IC}_{50}$ values were all less than $0.01 \mu \mathrm{M}$. For PPD12, the values had a wide range. PPD12 potently inhibited CYP2B6-catalyzed bupropion hydroxylation and CYP3A4-catalyzed midazolam 1 -hydroxylation, with $\mathrm{IC}_{50}$ values of 2.21 and $1.03 \mu \mathrm{M}$, respectively (Table II). PPD12 moderately inhibited
CYP3A4-mediated testosterone 6- $\beta$-hydroxylation and CYP2C8-mediated amodiaquine $\mathrm{N}$-deethylation with $\mathrm{IC}_{50}$ values of 8.43 and $9.57 \mu \mathrm{M}$, respectively. PPD12 weakly inhibited CYP2C19-catalyzed s-mephenytoin4'-hydroxylation and CYP2D6-catalyzed dextromethor phandextrorphan, with $\mathrm{IC}_{50}$ values of 15.04 and $11.85 \mu \mathrm{M}$, respectively. At $33 \mu \mathrm{M}$, PPD12 produced a negligible inhibition of CYP1A2-mediated phenacetin 0-deethylation and CYP2C9-mediated diclofenac4'-hydroxylation.

Plots of the plasma concentrations vs. time of PPD12 after oral and i.v. administration to male SD rats are shown in Fig. 2. For intravenous (i.v.) administration, the plasma concentration of PPD12 rapidly declined within the first $2 \mathrm{~h}$ but then was maintained at a high level, followed by a gradual linear decrease. The oral absolute bioavailability was $114.41 \pm 22.24 \%$

Evaluation of the toxicity of PPD12 in mice. To determine the maximum tolerant dosage of a single PPD12 treatment in the mice, we administered a high dosage of $1 \mathrm{~g} / \mathrm{kg}$ PPD12 to Balb/c mice. Interestingly, we did not observe any lethal effects, even at such a high level, which suggests that a severe and high-dosage treatment of PPD12 is well tolerated by and non-toxic to animals. After a chronic, low-dosage and long-term administration of PPD12 at $100 \mathrm{mg} / \mathrm{kg}$ for 3 weeks, we found that PPD12 did not markedly reduce the body weight in either female or male mice compared with the control group, as shown in Fig. 3. Similarly, compared with the control group, PPD12 incurred either no damage or, at most, an acceptable amount of damage to organs such as the heart, kidney, spleen and others that are not shown in this paper (Figs. 4 and 5).

These results all suggested that PPD12 exhibits low toxicity with either short- or long-term administration.

Evaluation of the combination treatment of PPD12 and ADM in mice. To further evaluate the role that PPD12 plays in ADM toxicity, we used the same method used for the single PPD12 treatment. Mice received ADM or a combination of ADM and 
Table II. Inhibitory effect of PPD12 on major CYP metabolic activities in human liver microsomes.

\begin{tabular}{|c|c|c|c|c|}
\hline \multirow[b]{2}{*}{ CYP enzyme } & \multirow[b]{2}{*}{ Catalysis } & \multirow[b]{2}{*}{ Inhibitor } & \multicolumn{2}{|c|}{$\mathrm{IC}_{50}(\mu \mathrm{M})$} \\
\hline & & & Inhibitor & PPD12 \\
\hline $3 \mathrm{~A} 4$ & Midazolam 1'-hydroxylation & Ketoconazole & 0.0040 & 1.03 \\
\hline $3 \mathrm{~A} 4$ & Testosterone $6-\beta$-hydroxylation & Ketoconazole & 0.0154 & 8.43 \\
\hline $1 \mathrm{~A} 2$ & Phenacetin 0-deethylation & $\alpha$-Naphthoflavone & 0.0168 & $>33$ \\
\hline 2B6 & Bupropion hydroxylation & Ticlopidine & 0.0823 & 2.21 \\
\hline $2 \mathrm{C} 8$ & Amodiaquine N-deethylation & Quercetin & 0.7319 & 9.57 \\
\hline $2 \mathrm{C} 9$ & Diclofenac4'-hydroxylation & Sulfaphenazole & 0.0856 & $>33$ \\
\hline $2 \mathrm{C} 19$ & S-mephenytoin4'-hydroxylation & Ticlopidine & 0.5120 & 15.04 \\
\hline 2D6 & Dextromethorphandextrorphan & Quinidine & 0.0235 & 11.85 \\
\hline
\end{tabular}

PPD12, 20(S)-protopanaxadiol derivative; CYP, cytochrome P450.
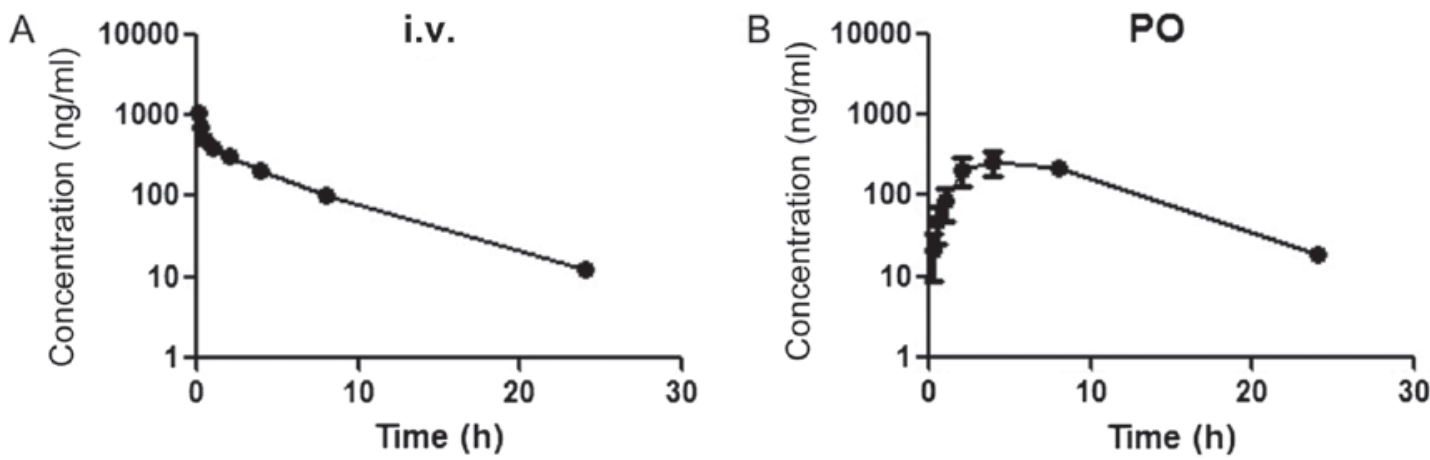

Figure 2. Plasma concentration vs. time profiles of PPD12 following its oral and i.v. administration in male SD rats. (A) Three SD rats received $10 \mathrm{mg} / \mathrm{kg}$ PPD12 via i.v. administration.(B) Three SD rats received $10 \mathrm{mg} / \mathrm{kg}$ PPD12 via oral administration. i.v., intravenous; SD, Sprague-Dawley; PPD12, 20(S)-protopanaxadiol derivative; PO, oral administration.
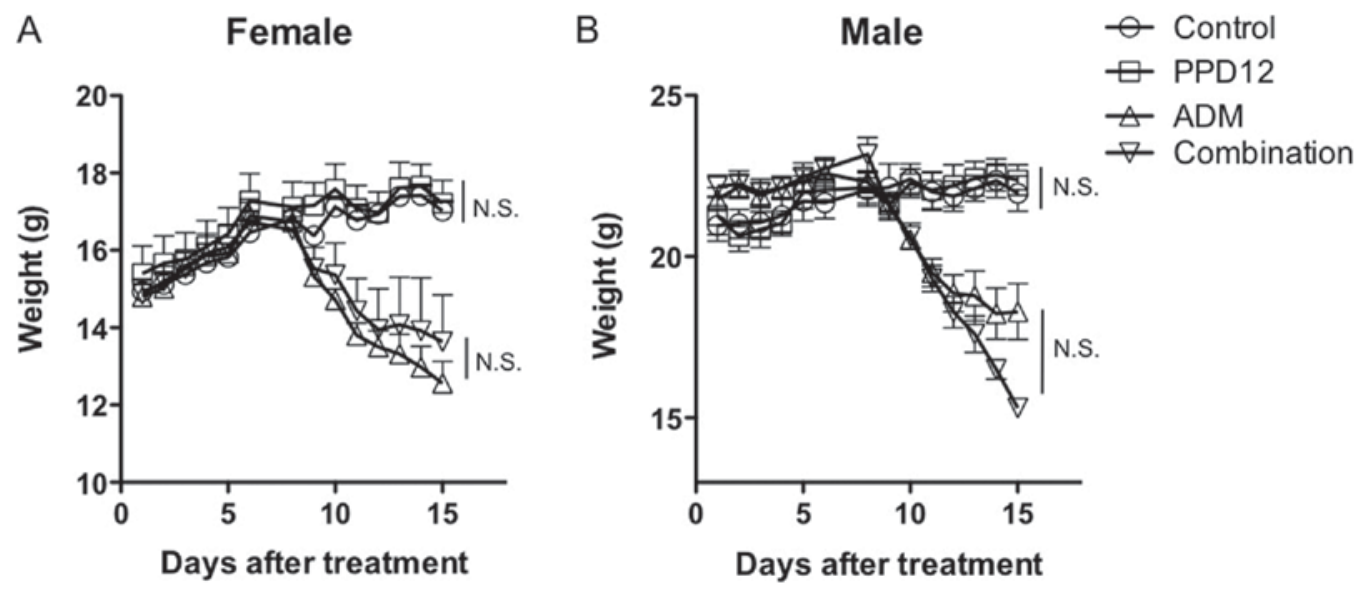

Figure 3. Changes in body weight following treatment with PPD12 or a placebo in combination with ADM in Balb/c mice. (A) For female Balb/c mice, the PPD12 and the combination group received $100 \mathrm{mg} / \mathrm{kg}$ PPD12 via oral administration twice a week for two weeks, while the ADM and combination group received a single treatment of ADM at $20 \mathrm{mg} / \mathrm{kg}$ i.p. on the 6 th day. (B) The male Balb/c mice received the same treatment as the females. N.S., no significant difference; PPD12, 20(S)-protopanaxadiol derivative; ADM, adriamycin.

PPD12, and the body weight, morphology of different tissues and apoptosis were examined. As shown in Fig. 3A, for female mice, a significant reduction in body weight was observed in both the ADM group and the ADM plus PPD12 group compared to the control group. However, neither the female nor the male mice exhibited significant evaluated body weight loss when the combination group was compared to the ADM alone group.

For tissue observations, we first observed the morphological changes in the hearts. We found that in the ADM group, the 


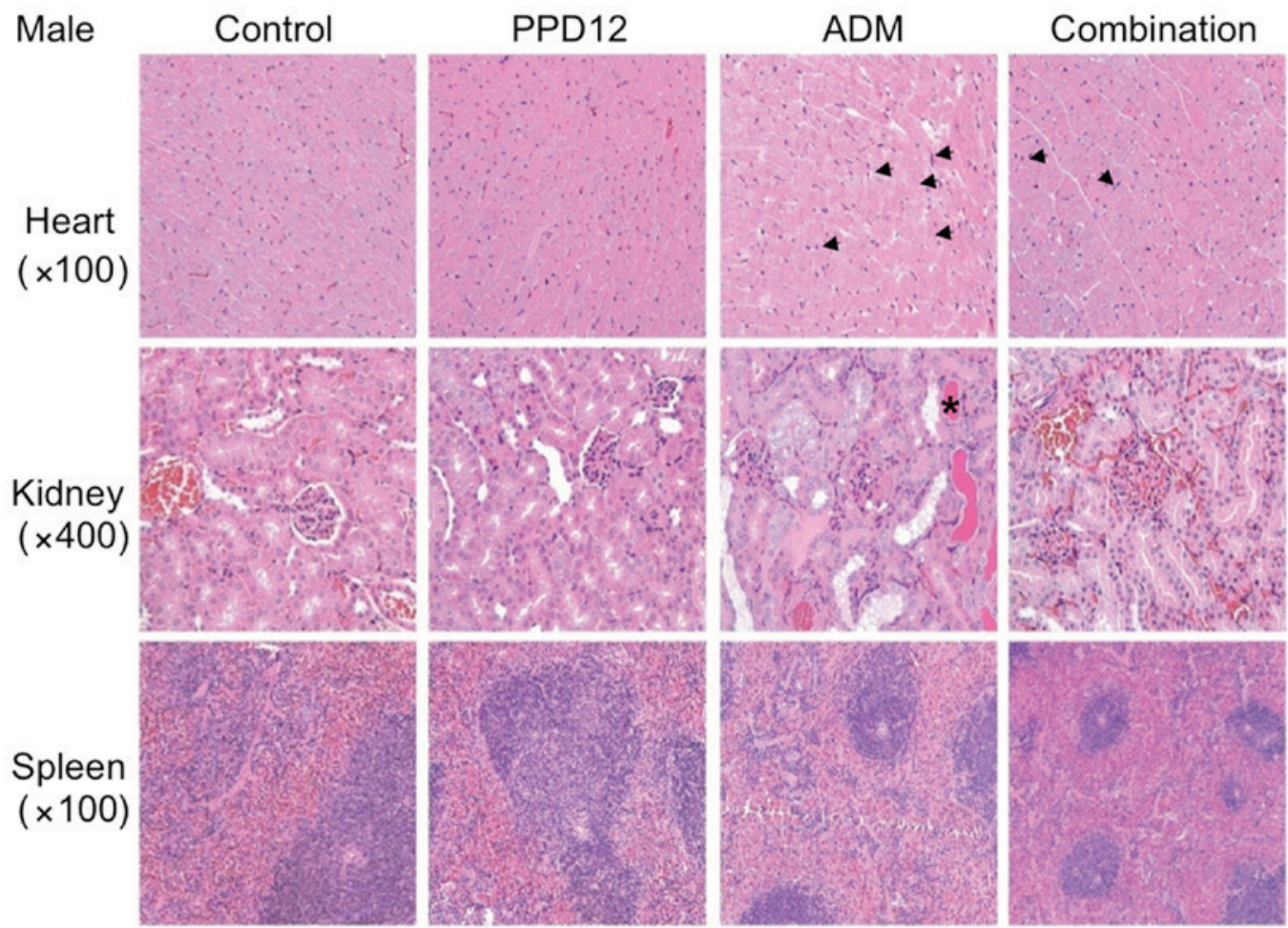

Figure 4. Hematoxylin and eosin staining assay for PPD12 alone or combined with ADM in male Balb/c mice tissues. PPD12 does not cause toxicity in the heart, kidney and spleen. Arrows indicate damaged heart cells and the asterisk labels the tube cast. PPD12, 20(S)-protopanaxadiol derivative; ADM, adriamycin.

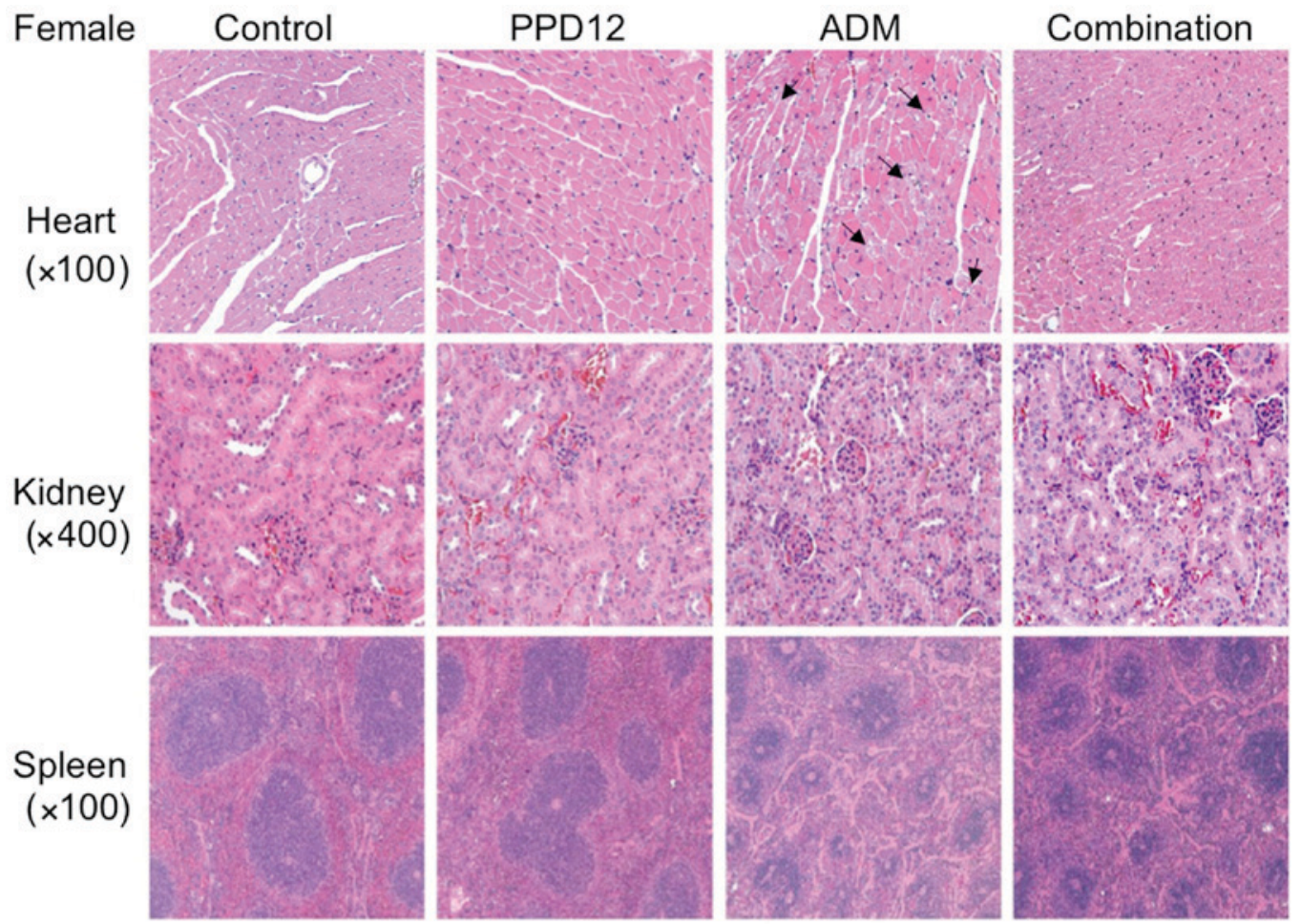

Figure 5. Hematoxylin and eosin staining assay for PPD12 alone or combined with ADM in female Balb/c mice tissues. PPD12 does not cause toxicity in the heart, kidney and spleen. Arrows indicate damaged heart cells. PPD12, 20(S)-protopanaxadiol derivative; ADM, adriamycin.

interstitial tissue was widened, and some myocardial cells became edematous, with pale red H\&E staining. Moreover, with ADM alone, much more obvious necrosis was observed in the treated female mice than in the male mice. However, these damages were slightly reduced by the combination of PPD12 and ADM. Furthermore, it seemed that PPD12 could reverse the cardiac toxicity of the female group to a level similar to that of the male group. 

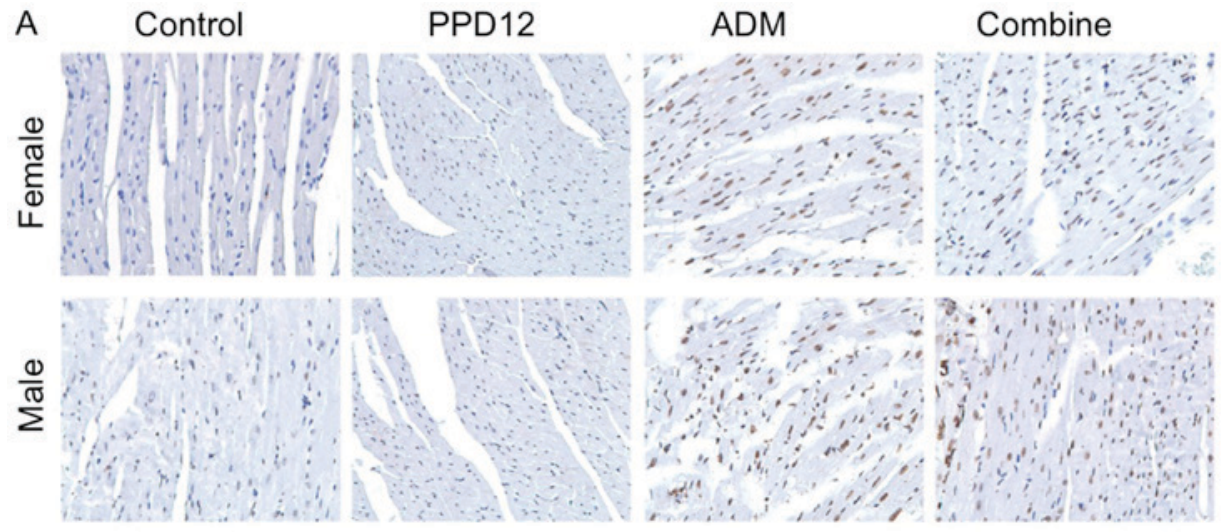

B
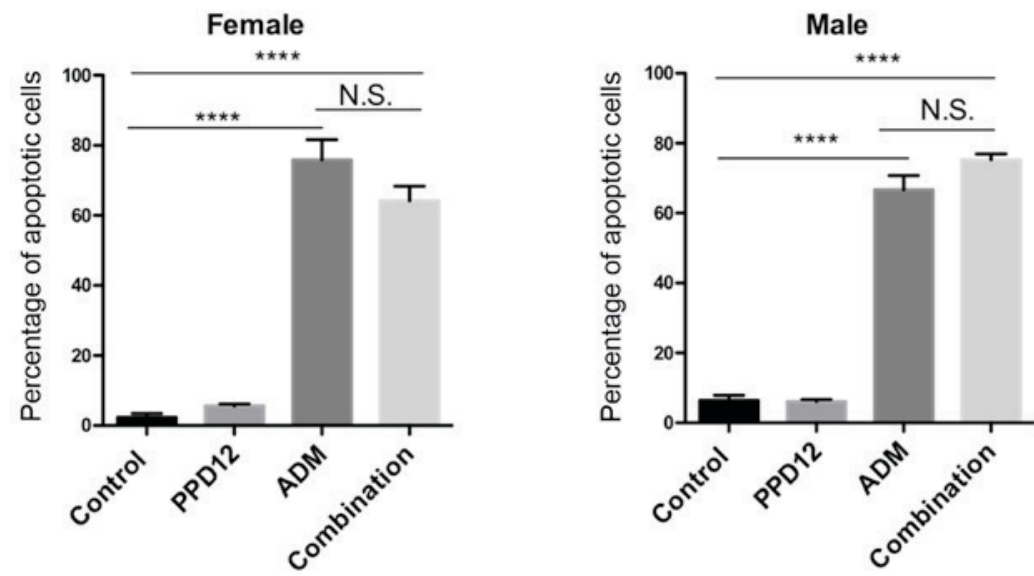

Figure 6. (A) TUNEL staining assay of heart tissues within the single groups of ADM and PPD12 or in the combination group of PPD12 and ADM in male and female Balb/c mice. Those with the nucleus stained brownish yellow are apoptotic cells. Magnification, x100. (B) Percentage of apoptotic cells in female and male mice. ${ }^{* * * * *} \mathrm{P}<0.0001$. N.S., no significant difference; PPD12, 20(S)-protopanaxadiol derivative; ADM, adriamycin.

We next focused on the kidney. In the ADM group, kidney epithelial cells were enlarged, and the cytoplasm was loose and contained vacuoles, and some of it was even necrotic. In contrast to the hearts of female and male mice, ADM did more damage to the kidneys of the male group, and a hyaline cast was much more common in male mice than in female mice. Nevertheless, co-treatment with PPD12 and ADM visibly reversed ADM's toxicity on the kidney PPD12, especially in the male group.

The spleen was also examined in this study. Whereas ADM alone treatment severely shrank the splenic nodule, narrowed the medullary cord and dilated and congested the splenic sinus, many types of lesser damage were observed following co-treatment with PPD12 and ADM, such as a larger spleen nodule.

To better distinguish damaged cells, we also performed specific staining to evaluate apoptosis. Cardio toxicity was the most common and serve adverse effect of ADM so the apoptosis in heart was analyzed. In the TUNEL assay of heart tissues (Fig. 6), there was no obvious difference in apoptotic cells between the control and PPD12 group but a significant increase in apoptosis in the single ADM group. The toxicity of PPD12 was well tolerated compared to ADM. Similar to the results of body weight loss, there was a significant increase in apoptotic cells in the combined and single ADM group compared to the control group. In addition, there was no obvious difference between the combination group and ADM group.

\section{Discussion}

ADM is an ordinary chemotherapy agent, but some treatments that use it result in failure. The MDR is one of the main causes responsible for such failures (22). Although targeting special molecules responsible for MDR, many clinical trials do not reach the third stage because the agents cannot reach a satisfactory effect at clinically tolerant doses.

Traditional herbal medicine, such as ginsenosides, have recently been gaining more attention for their natural constituents, biological activities and low toxicity (23). Among these ginsenosides, 20(S)-PPD is the main ingredient responsible for anti-neoplastic effects (24) and is the final active metabolite (25). To better improve its effectiveness, based on a structure analysis, we designed and synthesized PPD derivates and found that PPD12 is a prominent candidate. In a previous study, we demonstrated that PPD12 could sensitize multidrug-resistant cancer cells to chemotherapeutic agents in vitro and in vivo and that it worked to reverse MDR partly by inhibiting ABCB1 activity.

In the present study, we further found that PPD12 did not obviously alter the effect of ADM in KB cells. However, for the MDR cell line KB/VCR, PPD12 apparently strengthened the anticancer activity of ADM, reversed MDR at early time points and could maintain or even enhance this effect with increasing time. After $24 \mathrm{~h}$ of incubation, the addition of PPD12 to ADM achieved nearly an 18-fold reversal of MDR and attained a noteworthy decrease in cell viability. These 
findings all suggest the perfect anticancer and anti-MDR qualities of PPD12.

It is postulated that most metabolic drug-drug interactions can induce an inhibition or drug-metabolization of CYP450 enzymes (21) and that the inhibition of P450 s by ginsenosides can be attributed to ginseng-drug interactions (26). Different ginsenosides or ginsenoside extracts have different impacts on CYP450. In assays on a series of CYP450 activities, the $\mathrm{IC}_{50}$ values for PPD12 were significantly higher than those of the positive selective inhibitors that were used as positive controls; furthermore, PPD12 showed slight inhibition of the activities of CYP450 enzymes. PPD12 was also determined to be well absorbed in the mouse model, and the bioavailability of PPD12 was nearly $100 \%$ by oral administration.

We next evaluated the maximum tolerant dosage in the PPD12 alone treatment group. The results demonstrated that PPD12 was well tolerated in the mice tested, even in the $1 \mathrm{~g} / \mathrm{kg}$ treatment group. A chronic low-dose treatment of PPD12 also did not show any obvious influence on body weight, tissue morphology and apoptosis.

Furthermore, an additional treatment with PPD12 did not increase the toxicity of the chemotherapy drug ADM but did partly decrease the damage incurred by ADM. Interestingly, the PPD12-reduced kidney toxicity of ADM was more obvious in male mice than in female mice, whereas the PPD12-reduced cardio-toxicity of ADM, as shown by the contrast phenomenon, was more significant in female mice, in agreement with previous studies. Lipshultz et al stated that ADM cardiac toxicity was more severe in female patients than in male patients (27). Further, ADM cardiac toxicity occurred more readily in females than in males (28-30). In our studies, the cardiac toxicity of ADM was more serious in female mice. Sakemi et al reported that ADM treatment induced more massive nephropathy in male rats compared with female rats and that castration significantly reduced the nephropathy to an extent equal to the levels observed in female rats (31). In addition, H\&E staining showed that the damage in the kidney was more serious in male mice. Although the damage of ADM differed in the heart and kidney of the different sexes, the morphological modifications in the heart and kidney of the combination group remained at a similar level in both female and male mice. The toxicity of ADM alone had a wide range in female and male mice, which may have been due to sex hormones. This range could be reversed by the additional administration of PPD12. Based on the literature, ginsenosides share a backbone similar to estrogen hormones, and some have even been shown to bind to hormone receptors (32-35). Studies confirmed that melatonin could kill breast cancer cells, reduce cellular damage and mitochondrial degeneration of epirubicin and protect the integrity of the subcellular structure in doxorubicin-treated hearts via an estrogen signaling pathway (27). Therefore, PPD12 possibly helped to reduce the adverse effect of ADM because of the special structure shared by PPD12 and estrogen.

In conclusion, PPD12 was able to achieve and maintain satisfactory ADM-MDR reversal. PPD12 also exhibited low toxicity and high bioactivity and did not further increase the toxicity of ADM treatment. PPD12 is a promising candidate to help overcome MDR in cancer chemotherapy and is suitable for further clinical trials in tumor patients.

\section{Acknowledgements}

Not applicable.

\section{Funding}

The present study was supported by the Project of the Shanghai Science and Technology Committee (grant no. 14431905800$)$.

\section{Availability of data and materials}

The datasets used and/or analyzed during the current study are available from the corresponding author on reasonable request.

\section{Authors' contributions}

JP and XW designed the study. SW performed the experiments. XW, WC and LH analyzed the data and organized the study. XW and SW wrote the manuscript.

\section{Ethics approval and consent to participate}

The study was approved by the Ethics Committee of the Ninth People's Hospital [approval no. HKDL (2017) 126].

\section{Patient consent for publication}

Not applicable.

\section{Competing interests}

The authors declare that they have no competing interests.

\section{References}

1. Attele AS, Wu JA and Yuan CS: Ginseng pharmacology: Multiple constituents and multiple actions. Biochem Pharmacol 58: 1685-1693, 1999.

2. Xiang YZ, Shang HC, Gao XM and Zhang BL: A comparison of the ancient use of ginseng in traditional Chinese medicine with modern pharmacological experiments and clinical trials. Phytother Res 22: 851-858, 2008

3. Wang W, Rayburn ER, Hao M, Zhao Y, Hill DL, Zhang R and Wang H: Experimental therapy of prostate cancer with novel natural product anti-cancer ginsenosides. Prostate 68: 809-819, 2008.

4. Lee WM, Kim SD, Kim KS, Song YB, Kwak YS, Cho JY, Park HJ, Oh JW and Rhee MH: Protopanaxadiol modulates LPS-induced inflammatory activity in murine macrophage RAW264.7 cells. J Ginseng Res 30: 181-187, 2006.

5. Hui YZ, Yang ZR, Yang ZQ and Ge Q: Inventors; CN-KnowHow intellectual property agent limited, assignee. Antidepressant compositions containing 20(S)-protopanaxadiol extracted from ginsenoside. China Patent CN 200610027507.1: Jan 17, 2007.

6. Qi LW, Wang CZ and Yuan CS: American ginseng: Potential structure-function relationship in cancer chemoprevention. Biochem Pharmacol 80: 947-954, 2010.

7. Li G, Wang Z, Sun Y, Liu K and Wang Z: Ginsenoside 20(S)-protopanaxadiol inhibits the proliferation and invasion of human fibrosarcoma HT1080 cells. Basic Clin Pharmacol Toxicol 98: 588-592, 2006.

8. Liu GY, Bu X, Yan H and Jia WW: 20S-protopanaxadiol-induced programmed cell death in glioma cells through caspasedependent and -independent pathways. J Nat Prod 70: 259-264, 2007. 
9. Kasai R, Hara K, Dokan R, Suzuki N, Mizutare T, Yoshihara S and Yamasaki K: Major metabolites of ginseng sapogenins formed by rat liver microsomes. Chem Pharm Bull (Tokyo) 48: 1226-1227, 2000.

10. Li L, Chen X, Li D and Zhong D: Identification of 20(S)-protopanaxadiol metabolites in human liver microsomes and human hepatocytes. Drug Metab Dispos 39: 472-483, 2011.

11. Liu J, Wang X, Liu P, Deng R, Lei M, Chen W and Hu L: 20(S)-Protopanaxadiol (PPD) analogues chemosensitize multidrug-resistant cancer cells to clinical anticancer drugs. Bioorg Med Chem 21: 4279-4287, 2013.

12. Chen G, Liu J, Chen W, Xu Q, Xiao M, Hu L, Mao L and Wang X: A 20(S)-protopanoxadiol derivative overcomes multi-drug resistance by antagonizing ATP-binding cassette subfamily B member 1 transporter function. Oncotarget 7: 9388-9403, 2016.

13. Gurley BJ, Gardner SF, Hubbard MA, Williams DK, Gentry WB, Cui Y and Ang CY: Cytochrome P450 phenotypic ratios for predicting herb-drug interactions in humans. Clin Pharmacol Ther 72: 276-287, 2002.

14. Butterweck V and Derendorf H: Herb-drug interactions. Planta Med 78: 1399, 2012.

15. Nelson-Rees WA and Flandermeyer RR: HeLa cultures defined. Science 191: 96-98, 1976

16. Capes-Davis A, Theodosopoulos G, Atkin I, Drexler HG, Kohara A, MacLeod RA, Masters JR, Nakamura Y, Reid YA, Reddel RR and Freshney RI: Check your cultures! A list of cross-contaminated or misidentified cell lines. Int J Cancer 127 $1-8,2010$.

17. Qiu JG, Zhang YJ, Li Y, Zhao JM, Zhang WJ, Jiang QW, Mei XL, Xue YQ, Qin WM, Yang Y, et al: Trametinib modulates cancer multidrug resistance by targeting $\mathrm{ABCB} 1$ transporter. Oncotarget 6: 15494-15509, 2015.

18. Cai Q, Sun H, Peng Y,Lu J, Nikolovska-Coleska Z, McEachern D, Liu L, Qiu S, Yang CY, Miller R, et al: A potent and orally active antagonist (SM-406/AT-406) of multiple inhibitor of apoptosis proteins (IAPs) in clinical development for cancer treatment. J Med Chem 54: 2714-2726, 2011.

19. Jeong HU, Kong TY, Kwon SS, Hong SW, Yeon SH, Choi JH, Lee JY, Cho YY and Lee HS: Effect of honokiol on cytochrome P450 and UDP-glucuronosyltransferase enzyme activities in human liver microsomes. Molecules 18: 10681-10693, 2013.

20. Ma S, Li X, Dong L, Zhu J, Zhang H and Jia Y: Protective effect of Sheng-Mai Yin, a traditional Chinese preparation, against doxorubicin-induced cardiac toxicity in rats. BMC Complement Altern Med 16: 61, 2016.

21. Wienkers LC and Heath TG: Predicting in vivo drug interactions from in vitro drug discovery data. Nat Rev Drug Discov 4 $825-833,2005$

22. Vtorushin SV, Khristenko KY, Zavyalova MV, Perelmuter VM, Litviakov NV, Denisov EV, Dulesova AY and Cherdyntseva NV: The phenomenon of multi-drug resistance in the treatment of malignant tumors. Exp Oncol 36: 144-156, 2014.

23. Shi Z, Liang YJ, Chen ZS, Wang XW, Wang XH, Ding Y, Chen LM, Yang XP and Fu LW: Reversal of MDR1/P-glycoprotein-mediated multidrug resistance by vector-based RNA interference in vitro and in vivo. Cancer Biol Ther 5: 39-47, 2006.
24. Ren HC, Sun JG, Wang GJ, A JY, Xie HT, Zha WB, Yan B, Sun FZ, Hao HP, Gu SH, et al: Sensitive determination of 20(S)-protopanaxadiol in rat plasma using HPLC-APCI-MS: Application of pharmacokinetic study in rats. J Pharm Biomed Anal 48: 1476-1480, 2008.

25. Hasegawa $\mathrm{H}$ : Proof of the mysterious efficacy of ginseng: Basic and clinical trials: metabolic activation of ginsenosid: Deglycosylation by intestinal bacteria and esterification with fatty acid. J Pharmacol Sci 95: 153-157, 2004

26. Hao M, Zhao Y, Chen P, Huang H, Liu H, Jiang H, Zhang R and Wang H: Structure-activity relationship and substrate-dependent phenomena in effects of ginsenosides on activities of drug-metabolizing P450 enzymes. PLoS One 3: e2697, 2008

27. Lipshultz SE, Lipsitz SR, Mone SM, Goorin AM, Sallan SE, Sanders SP, Orav EJ, Gelber RD and Colan SD: Female sex and higher drug dose as risk factors for late cardiotoxic effects of doxorubicin therapy for childhood cancer. N Engl J Med 332: 1738-1743, 1995

28. Lanzarini L, Bossi G, Laudisa ML, Klersy C and Aricò M: Lack of clinically significant cardiac dysfunction during intermediate dobutamine doses in long-term childhood cancer survivors exposed to anthracyclines. Am Heart J 140: 315-323, 2000.

29. Silber JH and Barber G: 'Increased risk of cardiac dysfunction after anthracyclines in girls'. Med Pediatr Oncol 25: 130-131, 1995.

30. Sorensen K, Levitt G, Sebag-Montefiore D, Bull C and Sullivan I: Cardiac function in Wilms' tumor survivors. J Clin Oncol 13: 1546-1556, 1995

31. Sakemi T, Ohtsuka N, Tomiyoshi Y and Morito F: Sex difference in progression of adriamycin-induced nephropathy in rats. Am J Nephrol 16: 540-547, 1996

32. Gray SL, Lackey BR, Tate PL, Riley MB and Camper ND: Mycotoxins in root extracts of American and Asian ginseng bind estrogen receptors alpha and beta. Exp Biol Med (Maywood) 229: 560-568, 2004.

33. Lee YN, Lee HY, Chung HY, Kim SI, Lee SK, Park BC and Kim KW: In vitro induction of differentiation by ginsenoides in F9 teratocarcinoma cells. Eur J Cancer 32A: 1420-1428, 1996.

34. Lee YN, Lee HY, Lee YM, Chung HY, Kim SI, Lee SK, Park BC and Kim KW: Involvement of glucocorticoid receptor in the induction of differentiation by ginsenosides in F9 teratocarcinoma cells. J Steroid Biochem Mol Biol 67: 105-111, 1998.

35. Lee Y, Jin Y, Lim W, Ji S, Choi S, Jang S and Lee S: A ginsenoside-Rh1, a component of ginseng saponin, activates estrogen receptor in human breast carcinoma MCF-7 cells. J Steroid Biochem Mol Biol 84: 463-468, 2003. International (CC BY-NC-ND 4.0) License. 